\title{
Application of the economic theory of self-control to model energy conservation behavioral change in households
}

Berndt Lundgren and Mårten Schultzberg

Working Paper 2019:01

Division of Building and Real Estate Economics Division of Banking and Finance

Department of Real Estate and Construction Management

School of Architecture and the Built Environment KTH Royal Institute of Technology 
Application of the economic theory of self-control to model energy conservation behavioral change in households

\author{
Berndt Lundgren \\ Royal Institute of Technology, Department of Real Estate and \\ Construction Management, Division of Building and Real Estate \\ Economics, Stockholm, Sweden \\ Email: Berndt.lundgren@abe.kth.se \\ Mårten Schultzberg \\ Department of Statistics, Uppsala University, Sweden Email: \\ marten.schultzberg@statistics.uu.se
}

\begin{abstract}
:
Smart meters and in-house displays hold a promise of energy conservation for those who invest in such technology. Research has shown that households only have a limited interest in such technology and information is thus often neglected, with rather limited energy savings. Surprisingly few empirical investigations have a theoretical foundation that may explain what is going on from a behavioral perspective. In this study the economic theory of selfcontrol is used to model energy-efficient behavior in middle-income households in Sweden. Our results show that different levels of energy-efficient behavior do not really have any impact on the actual consumption levels of electricity. Instead, different beliefs exist of being energy-efficient, but the households do not act accordingly. Our results suggest that the payment time period should be changed to stimulate the monitoring of bills and to introduce a gaming strategy to change incentives for energy conservation.

Keywords: Energy use, Energy efficient, In-house displays, Mediation model, Smart meters, Two-level time serie

JEL Codes: C11, C81, D12, R22
\end{abstract}




\section{Introduction}

As discussed by Gram-Hanssen \& Darby (2018), the future success of the smart home movement in reducing energy consumption at the household level is questionable since the majority of households in the US have shown a weak interest in investing in such technology. Such a weak interest is partly dependent on a laissez- faire attitude towards saving energy. This is a worrying observation since the technology take-up by residents is slow: only a few percent of US households use smart home products. The Swedish Energy Market Inspectorate (2017) supports these findings since they report that it is difficult to increase demand-side flexibility due to low interest from residents in reducing their energy consumption, lack of technical equipment, limited range of smart devices and market barriers.

The Energy Demand Research Project (AECOM, 2011) involved four energy companies in the UK and over 60 ooo of their customers to test consumers' responses to different forms of information on saving energy, where 18300 residents had smart meters installed in combination with real-time displays. On average the total saving of electricity was found to be 3 percent. In a meta-study (Ehrhardt-Martinez et al, 2010) savings of electricity using smart meters and feedback by real-time displays were on average 6 percent. Some reasons for these moderate levels of energy conservation seem to be the customers having difficulties in understanding both how to use the equipment and the results. Another reason is that the residents seem to lack motivation to use the equipment. Wesley Schultz et al (2015) suggest that goals play an important role in encouraging energy savings and feedback using social norms are more efficient than feedback on kWh consumption and costs alone. So why don't energy savings using feedback and real-time displays exceed 6 percent?

Using the economic theory of self-control (Thaler \& Shefrin, 1981) there are reasons to believe that those who reduce their consumption levels of electricity after an intervention with feedback are those who believe they are price-sensitive and energy-efficient prior to the intervention. Our aim is to research whether this holds true and provide a plausible direction for increased energy savings. To do this, we will investigate whether residents who do not have smart meters or real-time displays installed have lower energy consumption if they believe they are price-sensitive and energy-efficient.

Our study shows that residents having beliefs of being price-sensitive and energy-efficient do not have lower energy consumption: such residents consume as much electricity as anyone else prior to an intervention. From our results we believe that feedback starts the process of energy conservation amongst individuals who, prior to the intervention, believe they are energy-efficient. Our results suggest that the effect of feedback can increase energy savings by changing the time point of payment to be prepaid and by providing incentives to reduce energy consumption by following a gambling strategy to increase motivation. Similar findings have also been made by Gilbert \& Graff Zinvin (2014) who point out how monetary costs may be salient to the agent due to an opaque system that allows consumption and cost to occur at different time points, thus causing an intermittency problem.

The explorative study consists of 102 residential tenants in Stockholm, living in multi-family rental apartment buildings without smart meters or in-house displays. The sample of residents is reasonably representative of average households in the area. In addition to their actual consumption of electricity, we measured their beliefs of having an energy-efficient behavior using theEnergy-Efficient Behavior Scale (Stragier et al, 2012) to compare their scores on the scale with their actual monthly consumption of electricity during the period 2010-2017. In order to investigate how income and being price sensitive 
or not affects the consumption of electricity for appliances we have added those variables to inform us about the behavior of the respondents.

Discrepancies between attitudes towards an energyefficient behavior and actual energy consumption of electricity are revealed using a two-level time series mediation model implemented in the dynamic structural equations modeling (DSEM) framework (Asparouhov, Hamaker \& Muthén, 2018). This is a two-level time series modeling framework which has not been used before in energy research, where time is modeled onlevel 1 and households are modeled on level 2. That is, the high frequency consumption data are modeled on level 1 using time series models with parameters such as mean, autocorrelation structure and seasonality, which were allowed to be specific for individual households. On level 2 any of these household-specific parameters can be related to the latent constructs defined by a factor model. That is, on level 2, the between-household level, a structural equation model is specified where the relationship between price sensitivity and consumption is mediated by the behavior of respondents. This model describes not only the relationship to mean consumption, but any dynamic aspect of the withinhousehold electricity consumption process.

Using DSEM our findings point to the fact that residents do not act according to their beliefs of being energy-efficient, instead households who believe they are price- and energy-efficient turn out to consume as much electricity as anyone else. The implications of these findings are discussed as well as suggestions for policy changes.

The rest of this paper is organized as follows: Section 2 presents related literature and the theoretical framework is discussed in section 3; Section 4 describes the design of the empirical study together with related statistical tools; Section 5 gives the statistical results; finally, Section 6 contain conclusions and discussion.

\section{Literature review}

In the late 90 and early 2000s, research on how to present energy information suggested that electricity companies should include graphs in the billing information showing actual and historical consumption levels and also make comparisons to reference households, to further reduce consumption of electricity. However, despite these methods energy conservation is still difficult to achieve at the household level (RAND Europe, 2012). Curbing the demand for energy is a key question: Wilhite \& Ling (1995) suggest that better energy billing feedback leads to more energy-conscious consumers. However, several studies have shown that information on electricity consumption alone is not efficient in reducing energy use (Gram-Hanssen, 2014), whereas other studies claim the opposite (Henryson et al, 2000). Some studies state that information results in higher knowledge levels, but not necessarily in behavioral changes or energy savings (Abrahamse et al, 2005; Darby, 2006). Gaskell et al (1982) argue that decreases in energy consumption are most effectively achieved by supplying groups of householders with information on energy use and, at the same time, asking them to read meters daily. Gilbert \& Graff Zinvin (2014) found a reduction of electricity use of o.6-1.o percent in the week after receiving a bill which provides empirical evidence that monitoring energy bills has an effect on energy conservation, which however decreases over time until the next billing period. As the authors argue, costs that are salient are prone to encourage overconsumption due to incomplete feedback information. Sexton et al (1987) argue that a debit system, where it is possible to consume electricity and pay later, makes the consumer unaware of the actual costs. 
To deal with the problem of salient cost information, smart meter devices have been heavily researched because of their promise to reduce energy consumption by providing feedback in real time. A smart meter can show the consumption of electricity to residents through a panel, often placed on the wall, or by an app on a smart phone/tablet. In general, the conservation effect of smart meters and in-house displays is between 1.5-6.o percent depending on research circumstances (Ehrhardt-Martinez et al, 2010; Darby, 2006; AECOM, 2011). According to Henryson et al (2000) and Gregory \& Harrigan (1997), information in elaborated and tailored electricity bills, showing graphs that compare actual and historic consumption per month related to a reference group, provided a lasting reduction in electricity. Being given answers to questions like "Does our energy consumption diverge from the average?" contributed to reducing the energy consumption of households by means of social norms (Wesley Schultz et al, 2015).

Energy conservation also seems to be greater if tailored information is combined with concrete energy-saving advice. Using qualitative interviews, Gram-Hanssen et al (2004) found a correlation between a "saver" and a "spender" attitude to electricity. A saving behavior may originate in a need to save money, on deep-rooted habits or a conscious wish to act in an environmentally friendly way. Another promising way of conserving energy is by using electric tariff structures with progressive block pricing that aim to create incentives to conserve electricity by combining informative billing and displaying how close the customers are to reaching a threshold where the price for electricity increases. An important question to answer is how large the effect of price sensitivity is on an energy conservation behavior. From economics literature it is known that sample characteristics such as age, income, type of building and the standard of apartment, as well as the location of the home, impacts price elasticity. Elasticity may vary, for example, between -0.33 and-o.66 (Nesbakken, 1999), -0.51 and-1.32 (Bernard et al, 2010) or -0.86 and -0.67 (Gilbert \& Graff Zinvin, 2014). The latter authors have shown that when the price increases households tend to choose less energy-intensive appliances.

\section{Theoretical framework}

The economic theory of self-control (Thaler \& Shefrin, 1981) is founded on modeling the individual as an organization to incorporate the choice of consuming today or in the future. Making these choices individuals are assumed to have two sets of preferences that are in conflict over time. Individuals are acting as far-sighted planners and myopic doers at the same time. The concept of a two-self economic man opens up for the theory of self-control since the planner can impose inter-temporal choices that affect the actions of the doer.

According to the economic theory of self-control the doer is assumed to have direct control over consumption in any given time period. The planner affects the doer's actions by modifying preferences or changing incentives. The utility function of the doer may be changed by a set of preference modification parameters which are decided by the planner. By utilizing modification parameters any consumption level may be chosen.

As discussed by Thaler \& Shefrin (1981), there are three different techniques which can be used to alter the doer's consumption pattern. Firstly, the doer's preferences can be modified directly by the planner. Secondly, preferences can also be modified by monitoring and registering, e.g., as for calories consumed in a diet program. Preferences may also be altered by setting up weekly budgets that directly constrain consumption. Thirdly, the planner may change incentives to steer the behavior of the doer: Thaler \& 
Shefrin discuss an academic who agrees to present a paper at a conference that provides incentives for doing so. In addition to incentives and preferences, rules may be applied to restrict the doer's opportunities, for example when the price of monitoring the doer is too high. Some rules prohibit certain behavior and less extreme rules, for example budget constraints limit activities performed by the doer. The incentive to save energy is similar to setting and operating within a budget, being price-sensitive or to a diet program where the consumption of calories can be controlled.

To illustrate these techniques within an energy framework: Incentives to save energy may stem from monitoring information on energy consumption by energy bills or smart phones. Following the plannerdoer model we define monitoring activities as being performed by the planner, who can influence the doer by incentives to perform cutting or upgrading activities. A cutting activity can be the tenant switching off the light when leaving an empty room or turning off the electrical switch on a TV or computer. The tenant may be influenced by monitoring energy bills to upgrade to low-energy appliances, thus being energy-efficient. If the tenant is price-sensitive, we expect to find that a monitoring behavior will have an impact on energy-saving behaviors. Furthermore, we expect to find a positive relationship between being energy conscious and actual electricity consumption. Combining behavior data and actual electricity use allows us to study whether energy consciousness matters for an energy-efficient behavior in our sample.

\subsection{Research hypothesis}

Gilbert \& Graff Zinvin (ibid) point out how monetary costs may be salient to the agent due to an opaque system that allows consumption and cost to occur at different time points, thus causing an intermittency problem. These findings are also relevant to our study since they show how price affects energy consumption. However, the literature on economic behavior is not clear on how and on what grounds subjective beliefs of being price-sensitive and energy-efficient affect consumption of electricity. Could it be that beliefs of being price-sensitive and energy-efficient reduce energy consumption? Or is it rather that some people have an energy-efficient attitude, but despite this, they consume as much electricity as people without this attitude? If the price of electricity matters, we should observe an energy-efficient behavior amongst those respondents who claim to be price-sensitive and thus be able to predict their electricity consumption. In figure 2, we show a schematic mediation model used to describe how price sensitivity affects an energy-saving behavior according to the economic theory of self-control (Thaler \& Shefrin, ibid). Thaler \& Shefrin postulate that the planner controls the doer's actions using constraints and incentives. The monitoring activity is performed by the planner reading monthly or weekly bills showing the consumption of electricity or by following consumption in more detail using devices such as smart meters or a computer or mobile phone app. In our model we have added beliefs of being pricesensitive to investigate both direct and indirect effects on respondents who are sensitive towards the price of electricity. 
A price- sensitive household has reason to monitor consumption more often to make sure the cost does not become too high, and to try to cut down electricity consumption to lower the cost.

To reveal whether the respondents' beliefs of them performing energy-saving activities, such as upgrading or cutting, affect their actual consumption of electricity we correlated their beliefs to their actual monthly consumption of electricity 2010-2017. Wehypothesize that the effect of income and beliefs of being price-sensitive will have a direct effect on energy consumption, see figure 1. However, attitudes to the price of electricity should also be mediated through monitoring and energy-saving activities according the planner-doer model, such as cutting down on electricity use by turning off appliances or upgrading to energy-efficient appliances such as low-energy bulbs, or energy-efficient freezers or washing machines. We therefore hypothesize that increased price sensitivity will result in an increase in monitoring and energy-saving activities, again usingthe economic theory of self-control to predict behavior.

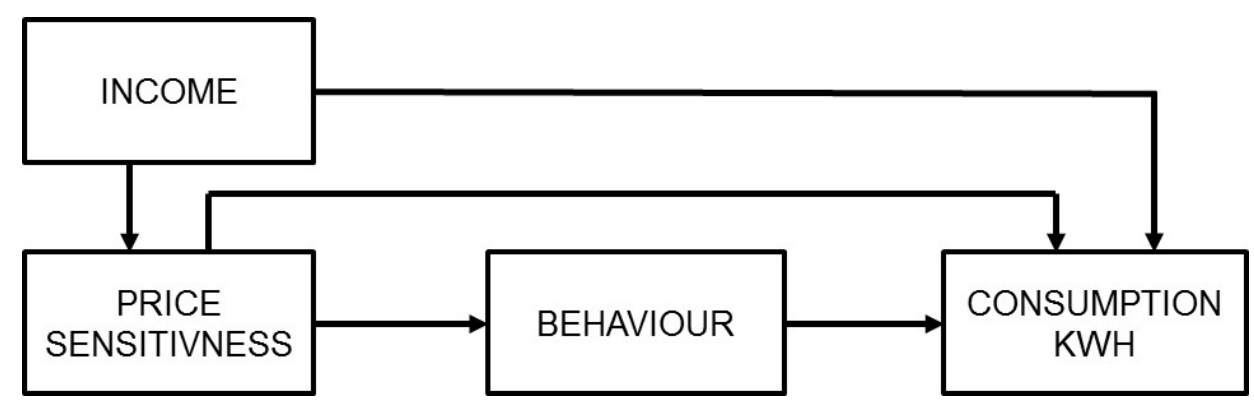

Figure 1. The planner-doer model within an energy framework. 


\section{Empirical approach}

The Energy-Efficient Behavior scale (Stragier et al, 2012) was developed to measure energy-efficient behavior in households and was tested in two large studies in The Netherlands, involving N=703 and N= 767 respondents. Principal component analysis (PCA) with Varimax rotation was used to define a fivefactor solution, further confirmatory factor analysis confirmed the five-factor solution and the validity of the factors. According to Pierce et al (2010), energy conservation behavior can be categorized into cutting, trimming, switching, upgrading and shifting activities. In the work with the EEB scale, the monitoring activity was added by Stragier et al (ibid) to account for information and feedback processes on consumption of electricity.

In our study the monitoring, cutting and upgrading factors have been used, however, trimming, switching and shifting are not used since those activities pre-suppose, for example, the possibility of regulating the temperature in a room by individual thermostats, which are known to be absent from the rental apartments in our study. In addition to the EEB scale, we add the latent construct of price sensitivity which is constructed to measure an attitude towards consuming electricity depending on price, thus we measure price sensitivity by asking about how important price is to their energy consumption, see the questionnaire in table 1. The items in the EEB scale are measured using a 5-point scale: never, rarely, sometimes, often and always.

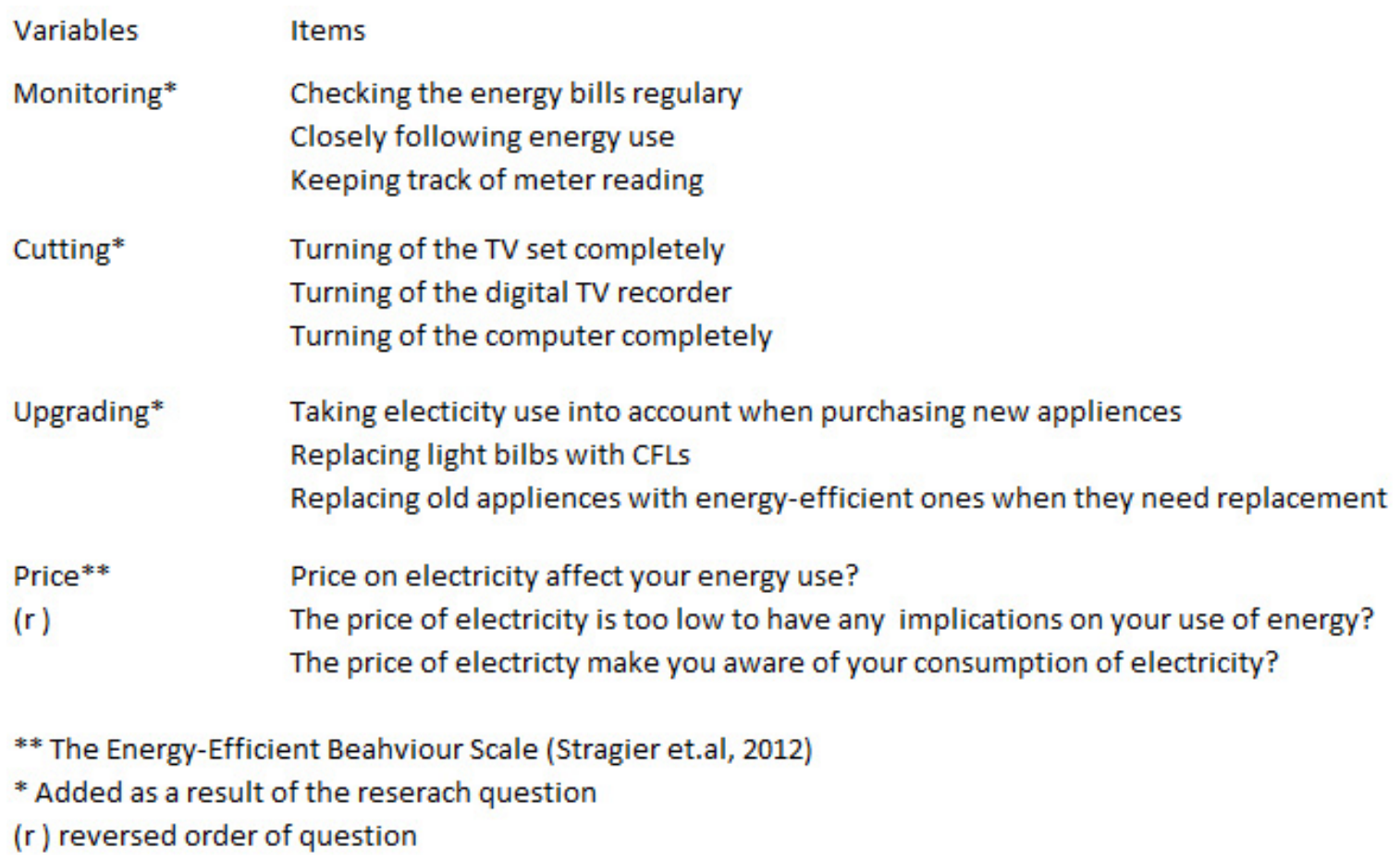

Table 1. Categories and items used in the research study. *The Energy-Efficient Behaviour Scale (Stragier et. at, 2012). **Price is added to the orginial scale due to the research question. (r) Reversed order of question. All questions are measured on 5-point Likert scales. Notes: The wording in the questionnaire are translated into Swedish and have the same meaning as the original question in English. 
The three statements for price sensitivity were measured using a 5-point Likert scale ranging from totally disagree to totally agree. For the actions under "Monitoring", "Cutting", and "Upgrading", the respondents had to indicate to which extent they actually consciously try to undertake conserving energy actions. Figure 2 displays the response rate for the 12 survey questions. There is large variation in all 12 questions, indicating that the questions successfully captured differences across the residents.
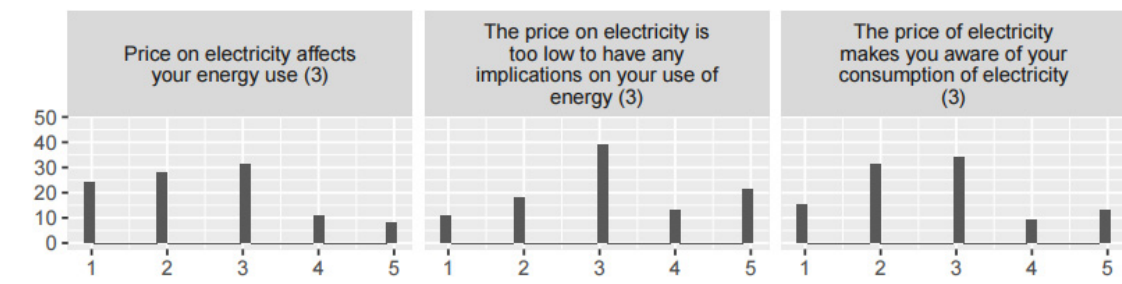

Checking the energy bills regularly (3)

Closely following energy use (2)

Keeping track of meter reading (1)
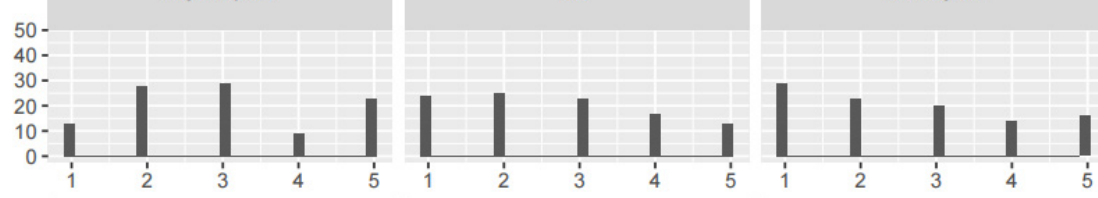

등 Turning off the TV set
completely (5)

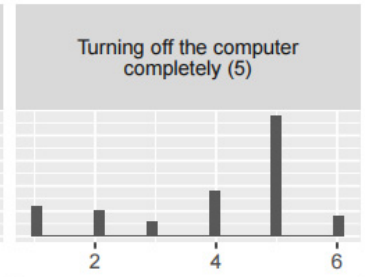

Leaving lights on (3)

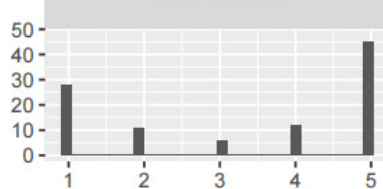

Taking electricity use into ccount when purchasing new appliances (4)
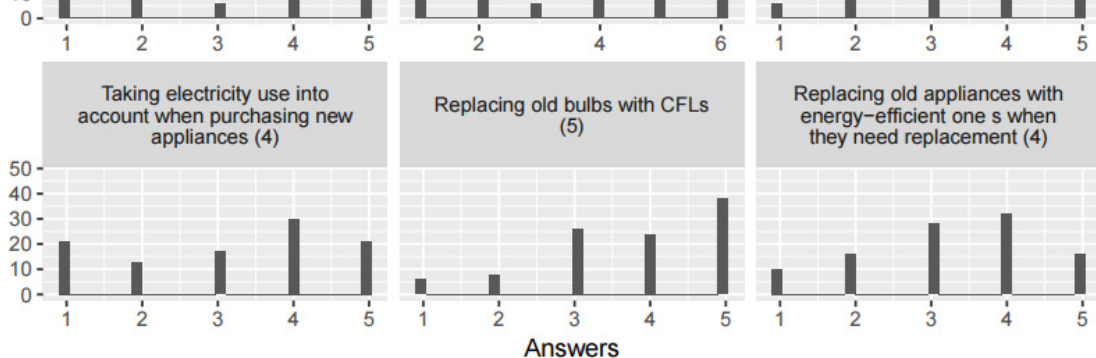

Replacing old appliances with energy-efficient one s when
they need replacement (4)

Figure 2. Response rate for the 12 survey questions. The values within parenthesis are the mode of the response. Note that the question regarding turning of the computer has a 6th category "I have no computer".

\subsection{The survey}

Longitudinal data on electricity consumption between the years 2010 and 2017 was collected from the sample of 510 middle-income households. The questionnaire was distributed via the Web over a period of three months in fall 2017, being sent to households living in multi-family rental apartment buildings built 2005-2010. A survey was distributed to the respondents and an introductory letter explaining the purpose of the study was included. Both a paper version of the study as well as a web-based questionnaire were offered to respondents. A reminder was sent to those who did not answer after three weeks and a second reminder after six weeks. After a review of incomplete answers 102 complete questionnaires provided a response rate of 20 percent.

The multi-tenant apartment buildings are owned by Svenska Bostäder which is a public housing company in Stockholm and one of Sweden's largest housing companies. The apartments are located in the borough of Hässelby/Vällingby, which is in the western part of Stockholm with a population of 68 ooo inhabitants. The majority of the building stock was built between 1960 and 1975 . However, we chose 
apartments built no earlier than 2005 to ensure a reasonably equal technical standard.

\begin{tabular}{ccc} 
Number of bedrooms & Frequency & Percent \\
Studio & 41 & 40,2 \\
1 & 31 & 30,4 \\
2 & 11 & 10,8 \\
3 & 16 & 15,7 \\
4 & 2 & 2,0 \\
5 & 1 & 1,0 \\
\hline & 102 & 100,0
\end{tabular}

Table 2. Distribution of number of rooms in the survey data $(\mathrm{N}=102)$.

One- and two-bedroom apartments were the most frequent type and the average size of apartments was $68 \mathrm{sqm}$ ( $\min 43$ and max $121 \mathrm{sqm}$ ), see table 2. Average income before tax in the borough of Hässelby/Vällingby is 325900 SEK ( 38600 USD/year) compared with average income before tax in the sample: 503200 SEK (59 700 USD/year). The sample shows a 54 percent higher than average income and a higher than average educational level and age compared to Hässelby/Vällingby as a whole.

\begin{tabular}{llcc}
\multirow{4}{*}{ Gender } & & Sample \% & Hässelby/Vällingby \% \\
\multirow{4}{*}{ Age } & Male & 52.9 & 52.2 \\
& Female & 47.1 & 47.7 \\
& $20-29$ & 5.1 & 18.5 \\
& $30-39$ & 17.1 & 20.7 \\
& $40-49$ & 25.0 & 18.7 \\
\multirow{4}{*}{ Education } & $50-64$ & 40.0 & 22.8 \\
& $65+$ & 12.1 & 19.2 \\
& Lower & 11.4 & 22.5 \\
& Basic & 34.1 & 40.2 \\
& Higer & 54.5 & 31.5
\end{tabular}

Table 3. Distribution of gender, age, and education in the survey data $(\mathrm{N}=102)$. The Hässelby/Vällingby data is from 2016.

On average, a family in Sweden living in a multi-family apartment building uses 2 ooo kWh per year. However, in the sample of 102 apartments the average consumption of electricity for appliances was 2 $143 \mathrm{kWh}$ per year, which is 7 percent higher. The questionnaire consisted of relevant socio-economic data within the Hässleby/Vällingby area to make sure that the sample was relatively consistent with the population, see table 3 . 


\subsection{Mediation and regression analysis}

This section describes the statistical model used to test the relationships implied by the economic theory of self-control. To be able to relate the high frequency measurements of the final outcome variable, i.e., the electricity consumption of each household, a two-level time series model with time on level 1 and households on level 2 is utilized. It is common to use the within-household sample mean of electricity consumption as the only measure of electricity consumption. However, if, as in our study, the real interest lies in the relationship between electricity consumption behavior and other variables, it would be preferable if dynamic aspects of the electricity consumption could also be included in the analysis. To achieve this we use a DSEM two-level time series model. Figure 3 displays the model diagram for the DSEM model that was used. The model uses latent decomposition to decompose each household-specific time series on level 1 into a small set of parameters, in this case the mean, the autoregressive coefficient, the seasonality and the residual variance. The level 1 model is given by

$$
k W h_{i t}=\mu_{i}+\varphi_{i} k W h_{i t-1}+\varphi_{s i} \operatorname{Season}_{i t-1}+E_{i t},
$$

where $E_{i t} \sim N\left(0, \sigma^{2}\right)_{i}$ Equation 1 says that the electricity consumption $(\mathrm{kWh})$ at time $\mathrm{t}$ for household $\mathrm{i}$ is a function of household-specific mean consumption, the household's consumption during the previous time period, what season it is (spring, summer, fall, winter), a residual with mean zero and a householdspecific variance parameter. This implies that the time series for each household, containing hundreds of measurements, is reduced to 4 parameters captured by four latent variables in the two-level model. This can be compared to one parameter, such as would be used if, instead, the within-household mean is used as the only measure of electricity consumption.

After model evaluation, only three of the random coefficients from the level 1 model are used as final outcomes in the level 2 model: the random mean, the random slope of the seasonal dummy (summer vs. winter), and the random residual variance. The between-level mediation model is given by the system of equations

$$
\begin{aligned}
& \text { Price }_{i}=\zeta_{0}+\zeta_{1} \text { Income }_{i}+ \\
& v_{i} \\
& \text { Monitoring }_{i}=a_{0}+a_{1} \text { Price }_{i}+\zeta_{i} \\
& \text { Cutting }_{i}=\gamma_{10}+\gamma_{11} \text { Monitoring }_{i}+\kappa_{1 i} \\
& \text { Upgrading }_{i}=\gamma_{20}+\gamma_{21} \text { Monitoring }_{i}+\kappa_{2 i} \\
& \mu_{i}=\beta_{10}+\beta_{11} \text { Price }_{i}+\beta_{12} \text { Monitoring }_{i}+\beta_{13} \text { Cutting }_{i}+\beta_{14} \text { Upgrading }_{i}+\beta_{15} \text { Income }_{i}+\xi_{1 i} \\
& \varphi_{s i}=\beta_{20}+\beta_{21} \text { Price }_{i}+\beta_{22} \text { Monitoring }_{i}+\beta_{23} \text { Cutting }_{i}+\beta_{24} \text { Upgrading }_{i}+\beta_{25} \text { Income }_{i}+\xi_{2 i} \text { log } \\
& \left(\sigma^{2}\right)_{i}=\beta_{30}+\beta_{31} \text { Price }_{i}+\beta_{32} \text { Monitoring }_{i}+\beta_{33} \text { Cutting }_{i}+\beta_{34} \text { Upgrading }_{i}+\beta_{35} \text { Income }_{i}+\xi_{3 i} \\
& \varphi_{s i}=\beta_{40}+\xi_{4 i}
\end{aligned}
$$


where the covariance matrix of the residuals is restricted as follows

$$
\left[\begin{array}{c}
\nu_{i} \\
\zeta_{i} \\
\kappa_{1 i} \\
\kappa_{2 i} \\
\xi_{1 i} \\
\xi_{2 i} \\
\xi_{3 i} \\
\xi_{4 i}
\end{array}\right] \sim N_{8}\left(\mathbf{0},\left[\begin{array}{cccccccc}
\sigma_{\nu}^{2} & 0 & 0 & 0 & 0 & 0 & 0 & 0 \\
0 & \sigma_{M o n}^{2} & 0 & 0 & 0 & 0 & 0 & 0 \\
0 & 0 & \sigma_{C u t}^{2} & \sigma_{C u t, U p g} & 0 & 0 & 0 & 0 \\
0 & 0 & \sigma_{C u t, U p g} & \sigma_{U p g}^{2} & 0 & 0 & 0 & 0 \\
0 & 0 & 0 & 0 & \sigma_{\mu}^{2} & \sigma_{\mu, \phi_{s}} & \sigma_{\mu, \log \sigma^{2}} & \sigma_{\mu, \phi} \\
0 & 0 & 0 & 0 & \sigma_{\mu, \phi_{s}} & \sigma_{\phi_{s}}^{2} & \sigma_{\phi_{s}, \log \sigma^{2}} & \sigma_{\mu, \phi} \\
0 & 0 & 0 & 0 & \sigma_{\mu, \log \sigma^{2}} & \sigma_{\phi_{s}, \log \sigma^{2}}^{2} & \sigma_{\log \sigma^{2}} & \sigma_{\phi, \log \sigma^{2}}^{2} \\
0 & 0 & 0 & 0 & \sigma_{\phi, \mu} & \sigma_{\phi, \phi_{s}} & \sigma_{\phi, \log \sigma^{2}} & \sigma_{\phi}^{2}
\end{array}\right]\right)
$$

The between-household model essentially contains two parts: First, the measurement model of the latent constructs, excluded from the equations above to save space ${ }^{1}$. Secondly, the structural model, in this case a path model containing the mediation model with the effect of Price on the consumption parameter vector, mediated in three steps: First by price and monitoring and then, possibly, by cutting and/or upgrading. Finally, some control covariates are included. The residual variances of the latent variables, including the four time-series parameters, are all modeled. As can be seen in Equation 4.2 the covariance matrix of the residual is restricted, this is common practice in the mediation model for identification purposes, see e.g. T. Vanderweele (2015).

\footnotetext{
${ }^{1}$ Note that cutting is not treated as a latent variable due to problems with the measurement model for that construct. Instead principal components of the indicators are included as an observed covariate for completeness.
} 

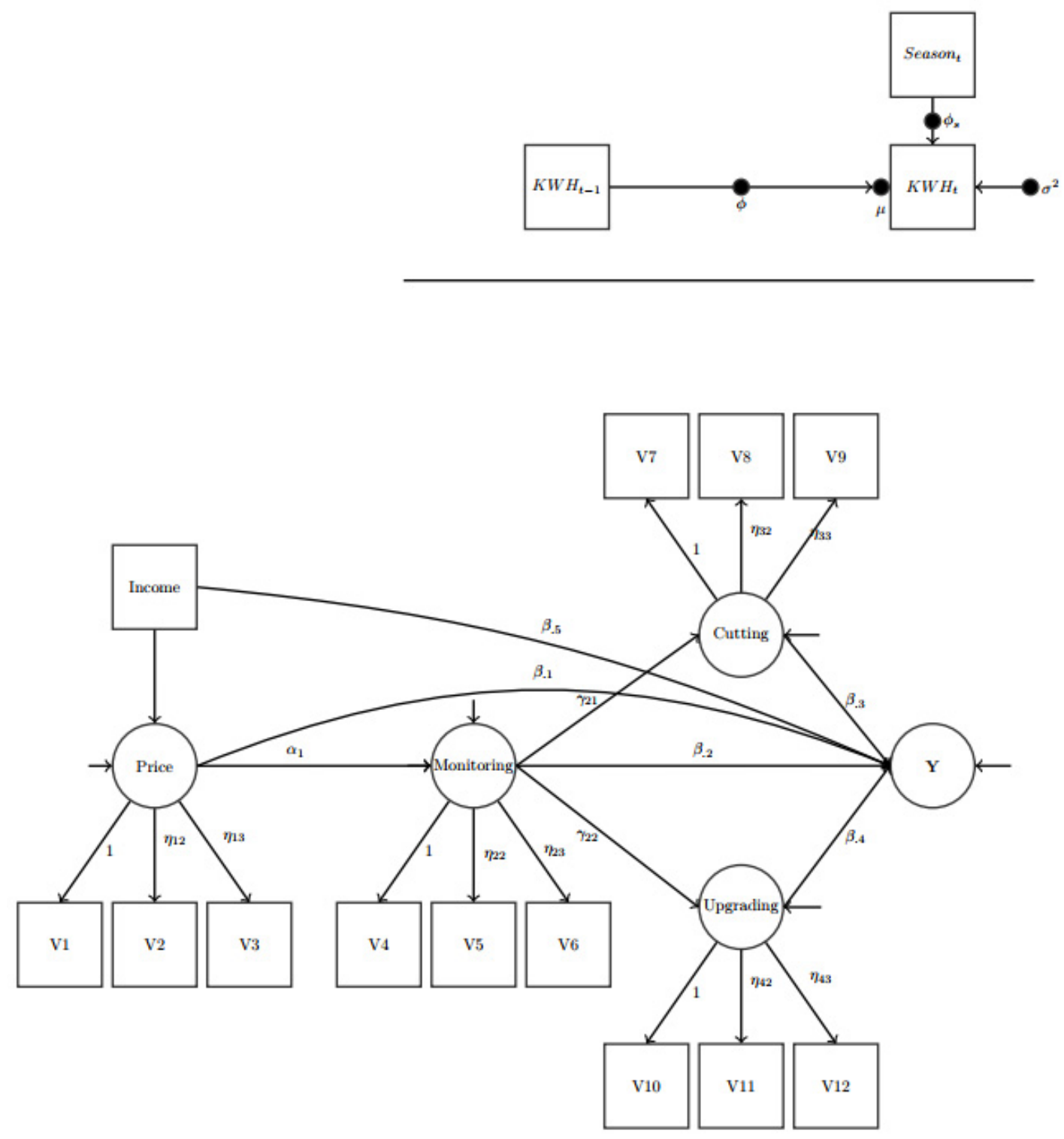

Figure 3. Model diagram for the two-level time series diagram. The upper part is the within-household (level-1) model and the lower part is the between-household (level-2) model. $\mathbf{Y}$ is a vector containing the three latent variables $\mu, \phi_{s}$, and $\log \sigma^{2}$.

In the model diagram of the level 2 model (lower part of figure 3), the random coefficients from the level 1 model are gathered in the vector $Y$ to reduce the number of arrows, wherefore the beta coefficients are all vectors containing the relationship to all elements of this vector. This model allows us to explore how price-sensitivity maps not only to mean consumption but also to the dynamic aspects of the consumption behavior captured by the autoregressive coefficient, seasonality, and residual variance. One way to think of the model in figure 3 is that is uses level 1 to reduce/condense the information in each household's electricity consumption time series, and that level 2 is an ordinary SEM model where the condensed information is available in terms of latent random variables. Note that the included control variables are excluded here to make the diagram clearer. 


\section{Results}

Table 4 displays the estimated structural equation model. Again, the measurement model of the between-level latent constructs is excluded to save space. The first column gives the name of the parameter, e.g. KWH ON INCOME is the slope of the regression of mean electricity consumption on income. The second column gives the point estimates, which by default in Mplus are the medians of the posterior distributions. The third column gives the estimated standard deviation of the posterior distributions, which corresponds to the standard errors of a frequentist model. The fourth column gives the most frequent type of p-value. The fifth and sixth columns give the upper and lower CI, based on the 2.5 percent and 97.5 percent quantiles of the posterior distributions. The last column indicates whether the corresponding estimate is significantly different from zero. For details on the Mplus Bayesian analysis output see Muthén \&Muthén (2017).

From the model estimates, we find that a high income is significantly associated with lower price sensitivity, higher mean consumption, smaller seasonality differences and larger residual variance. This is all in line with findings by Gilbert \& Graff Zinvin (2014). The smaller seasonality differences could be due to the fact that residents with higher income do not have to adjust their consumption to the seasonal differences in price. Price sensitivity is not directly significantly associated with the kWh consumption of electricity, although the signs of the relationship are in line with the planner-doer model of Thaler \& Shefrin. Higher price sensitivity is significantly associated with higher monitoring, which is also in line with Thaler \& Shefrin's planner-doer model. High monitoring has a significant association with high upgrading, which is supported by the planner-doer model and by findings obtained by Gilbert \& Graff Zinvin (2014), who have shown that when the price increases households tend to choose less energy-intensive appliances.

The relationship between monitoring and cutting is non-significant which is not expected by the planner-doer model, however, the relationship is positive, which is in line with the planner-doer model. Monitoring does not have a significant direct association with kWh consumption, which contradicts our theoretical model. Upgrading and cutting are non-significantly associated with kWh consumption, which we expect from the planner-doer model if the respondents consume electricity according to their beliefs. The latent variable cutting seems to be ill-defined by the items, which is also shown by the low Cronbach's Alpha (0.50), which indicates a poor fit. In summary, the latent constructs price sensitivity, monitoring and upgrading are significantly related to each other, as expected from economic theory of self-control (Thaler \& Shefrin,1981); however, they do not affect consumption when income is controlled for. It seems to be the case that residents with higher incomes plan their consumption less and spend more, maybe due to the fact that price does not really matter and the cost of electricity, according to their budget constraints, is not a significant part of their spending. Further, we have tested the five-factor solution using principal component analysis with Varimax solution with Kaiser normalization (0.641). The Kaiser test confirmed the five-factor solution. Investigating the consistency of different items loading on the variable was made using Cronbach's Alpha for monitoring (0.86), cutting (0.50) and upgrading (0.66). Price sensitivity (0.74) shows all acceptable values except for the variable cutting. 


\begin{tabular}{lllllll}
\hline Parameter & Estimate & Posterior sd & $\mathrm{p}$ & Lower & Upper & Significant \\
\hline Within & & & & & & \\
KWH ON SPRING & -0.173 & 0.008 & 0.000 & -0.189 & -0.157 & TRUE \\
KWH ON FALL & -0.079 & 0.008 & 0.000 & -0.095 & -0.063 & TRUE \\
& & & & & & \\
Between & & & & & & \\
PRICE ON INCOME & -0.126 & 0.055 & 0.005 & -0.250 & -0.031 & TRUE \\
PRICE ON AGE & 0.113 & 0.067 & 0.028 & -0.003 & 0.260 & FALSE \\
MONIT ON INCOME & 0.074 & 0.056 & 0.076 & -0.029 & 0.191 & FALSE \\
MONIT ON PRICE & 0.323 & 0.160 & 0.007 & 0.070 & 0.698 & TRUE \\
MONIT ON AGE & -0.037 & 0.071 & 0.298 & -0.169 & 0.111 & FALSE \\
CUTTING ON MONIT & 0.470 & 0.299 & 0.042 & -0.060 & 1.123 & FALSE \\
UPGRA ON MONIT & 0.638 & 0.324 & 0.000 & 0.228 & 1.496 & TRUE \\
& & & & & & \\
KWH ON INCOME & 0.114 & 0.034 & 0.001 & 0.047 & 0.179 & TRUE \\
KWH ON PRICE & 0.063 & 0.086 & 0.206 & -0.089 & 0.250 & FALSE \\
KWH ON MONIT & -0.035 & 0.086 & 0.330 & -0.211 & 0.130 & FALSE \\
KWH ON UPGRA & 0.086 & 0.070 & 0.043 & -0.013 & 0.249 & FALSE \\
KWH ON CUTTING & -0.049 & 0.026 & 0.027 & -0.099 & 0.001 & FALSE \\
KWH ON AGE & 0.033 & 0.064 & 0.305 & -0.094 & 0.157 & FALSE \\
& & & & & & \\
LOGV ON INCOME & 0.178 & 0.056 & 0.003 & 0.059 & 0.280 & TRUE \\
LOGV ON PRICE & 0.105 & 0.128 & 0.181 & -0.127 & 0.379 & FALSE \\
LOGV ON MONIT & -0.155 & 0.129 & 0.093 & -0.434 & 0.074 & FALSE \\
LOGV ON UPGRA & 0.087 & 0.096 & 0.112 & -0.059 & 0.307 & FALSE \\
LOGV ON CUTTING & -0.005 & 0.038 & 0.449 & -0.080 & 0.071 & FALSE \\
LOGV ON AGE & -0.115 & 0.095 & 0.111 & -0.303 & 0.070 & FALSE \\
& & & & & & \\
PHISUM ON INCOME & -0.031 & 0.008 & 0.000 & -0.046 & -0.016 & TRUE \\
PHISUM ON PRICE & -0.029 & 0.020 & 0.044 & -0.076 & 0.005 & FALSE \\
PHISUM ON MONIT & 0.018 & 0.019 & 0.153 & -0.017 & 0.060 & FALSE \\
PHISUM ON UPGRA & -0.016 & 0.014 & 0.068 & -0.050 & 0.006 & FALSE \\
PHISUM ON AGE & -0.017 & 0.014 & 0.118 & -0.044 & 0.011 & FALSE \\
\hline & & & & & &
\end{tabular}

Table 4: Estimation results. The first column gives the name of the parameter and the remaining columns the estimates with p-value and confidence interval. The last column indicates a relationship significantly different from zero. 


\section{Discussion}

In our exploratory study, we have shown how beliefs of being price-sensitive and energy-efficient do not affect consumption of electricity prior to an intervention with smart meters and real-time displays. This is clear from the insignificant relationships in the monitoring-cutting-upgrading and consumption of $k W h$ path. When we correlate such households' beliefs with their monthly consumption 2010 to 2017 they do not differ from anyone else in the sample, consuming just as much electricity. Since feedback has been proven to reduce electricity consumption by 1.5 to 6.0 percent (AECOM, 2011; Ehrhardt-Martinez et al, 2010) our results suggest that those who reduce their electricity consumption up to those levels are households who believe themselves to be energy-efficient and price-sensitive prior to the intervention. These households reach a threshold level by feedback that acts as a nudge to change their actual behavior. If we had made an intervention with in-house displays in our sample as a nudge to change behavior we would only have reached those households that have prior beliefs of themselves being energy-efficient and would probably reach a 1.5-6 percent reduction in the use of electricity. This means that it could be difficult to increase energy savings to over 6 percent using only feedback from real-time displays. To be able to further reduce electricity consumption we need to change the incentive structure and stimulate a saving behavior following Thaler \& Shefrin's economic theory of self-control.

We find a clear connection between the planner and the doer's actions following the theory of economic self-control since attitude to the price of electricity and monitoring and upgrading activities have significant relationships and correct signs. It is apparent that there is an effect of the planner, which has an impact on the beliefs of the respondent performing energy-saving activities such as upgrading to more energy-efficient appliances. From our results, it is likely that the doer had no or only weak influence with reference to saving electricity as a result of incentives that could encourage energy conservation being weak. This theory further suggests that if wefollow a calorie-counting scheme or a budgeting approach toward kWh consumption over a specific time period this would potentially solve the salience and intermittency problem as discussed by Gilbert \& Graff Zinvin (2014). The dominant system of payment for electricity worldwide, including in Sweden, is the post-paid system where the consumption of electricity is paid according to actual consumption after that consumption has taken place. Following the theory of economic self-control it stands to reason that the further away these time points of paying are, the weaker the incentives to promote an energy conservation behavior. International experiences from pre-paid electricity (Roberta et al, 2016) show that savings of 10-15 percent are possible, as opposed to those achievable for post-paid electricity. According to O'Sullivan et al (2014), pre-payment metering for electricity provides increased feedback to consumers that stimulates budgeting and management activities. Pre-paid electricity also allowed for micro budgeting and savings of electricity through the feedback households gained when controlling their meters. 
Pre-payment seems to have a strong influence on monitoring energy use. From the perspective of the theory of economic self-control both preferences and incentives are influenced by counting $\mathrm{kWh}$, as in a calorie-counting program. The incentives to save energy can be reinforced by introducing a gaming strategy where electricity not consumed is a penny saved into an account for rainy days or for refurbishment purposes. Given our empirical results and the direction given by the economic theory of self-control we argue that, to make electricity consumption less salient, households should not be billed a month after actual consumption but instead should buy electricity according to the pre-paid system and receive feedback in the form of social norm (Wesley Schultz et al, 2015).

\section{Limitations}

Because of estimation problems with the measurement model of cutting, the corresponding principal component is included in the analysis, instead of the latent variable, in order not to destabilize the rest of the model. As a result of this all interpretations, including cutting, should be made with caution. The problem is likely due to the small sample size in the survey data.

\section{Acknowledgment}

We acknowledge financial support from the Swedish Energy Agency (grant 2015-008440). We would like to thank Svenska Bostäder and Ellevio AB for their support and for providing data to this study. 


\section{References}

Abrahamse, W., Steg, L., Vlek, C. \& Rothengatter, T. (2005). A review of intervention studies aimed at household energy conservation. Journal of Environmental Psychology, 25, 273-291.

AECOM (2011). Energy Demand Research Project: Final Analysis, St Albans.

Asparouhov, T., Hamaker, E. \& Muthén, B. (2018) Dynamic structural equation models, Structural Equation Modeling: A Multidisciplinary Journal, 25, 359-388.

Bernard, J-T., Bolduc, D. \& Yameogo, N-D. (2010). A pseudo-panel data model of household electricity demand, Resource and Energy Economics, 33 (1), 315-325.

Darby, S. (2006). The Effectiveness of Feedback on Energy Consumption, Environmental Change Institute, Oxford, UK.

Ehrhardt-Martinez, K., Donnelly, K.A. \& Laitner, S. (2010). Advanced metering initiatives and residential feedback programs: A meta-review for household electricity-saving opportunities, American Council for an Energy-Efficient Economy.

Gaskell, G., Ellis, P.\& Pike, R. (1982). The energy literate consumer: the effects of consumption feedback and information on beliefs, knowledge and behavior. Dept of Social Psychology, LSE, London

Gilbert, B. \& Graff Zinvin, J. (2014). Dynamic salience with intermittent billing: Evidence from smart electricity meters, Journal of Economic Behavior \& Organization, 107, 176-190.

Gram-Hanssen, K., Kofod, C. \& Naervig Petersen, K. (2004). Different everyday lives - different patterns of electricity use. In proceedings of the 2004 ACEEE summer study on energy efficiency in buildings, Asilomar, Pacific Grove, CA, August 2004. Washington DC: American Council for an Energy-Efficient Economy.

Gram-Hanssen, K. (2014). New needs for better understanding of household energy consumptionbehavior. Lifestyle or practices, Architectural Engineering and Design Management, 10, 1-2, 91-107.

Gram-Hanssen, K. \& Darby, S. (2018). "Home is where the smart is"? Evaluating smart home research and approaches against the concept of home, Energy Research \& Social Science, 37, 94-101.

Gregory, J. \& Harrigan, S. (1997). Do savings from energy education persist? Presented to DA/DSM Europe '97 Conference, Amsterdam, The Netherlands. 
Henryson, J., Håkansson, T. \& Pyrko, J. (2000). Energy-efficiency in buildings through information Swedish perspective, Energy Policy, 28, 169-180.

Muthén, L.K. \& Muthén, B.O. (2017). Mplus User’s Guide. Eighth Edition. Los Angeles, CA

Nesbakken, R. (1999). Price sensitivity of residential energy consumption in Norway, Energy Economics, 21, 493-515.

O'Sullivan, K. C., Viggers, H.E. \& Howden-Chapman, P.L. (2014). The influence of electricity prepayment meter use on household energy behavior, Sustain Cities Soc, 13, 182-91.

Pierce, J., Schiano, D.J. \& Paulos, E. (2010). Home, Habits and Energy: Examining Domestic Interactions and Energy Consumption, Home Eco Behaviour, Atlanta, GA, USA.

RAND Europe (2012). What works in changing energy-using behaviours in the home? A rapid evidence assessment. Final report, November (http://webarchive.nationalarchives.gov.uk/20130103044334/http://www.decc.gov.uk climatechange/saving-energy-co2/6921-what-works-in-changing-energy-using-behaviours-in-.pdf). (Accessed 10th January 2018).

Roberta, G., Esteves, Z., Oliveira, F.L.C., Antunes, C.H. \& Souza, R.C. (2016). An overview of electricity prepayment and the Brazilian new regularity framework, Renewable and Sustainable Energy Reviews, 54, 704-722.

Sexton, R.J., Brown Johnson, N. \& Konakayama, A. (1987). Consumer Response to Continuous-Display Electricity-Use Monitors in a Time-of-Use Pricing Experiment, Journal of Consumer Research, 14, 55-62.

Stragier, J., Hauttekeete, L., Marez, L.D. \& Brondeel, R. (2012). Measuring Energy-Efficient Behaviour in Households: The Development of a Standardized Scale, Ecopsychology, 4 (1), 64-71.

Swedish Energy Market Inspectorate. Measures to increase demand side flexibility in the Swedish electricity system, Ei R2017:10. www.ei.se.

Thaler, R.H \& Shefrin, H.M. (1981). An Economic Theory of Self-Control, Journal of Political Economy, 89 (2), 392-406.

Vanderweele, T. J. (2015). Explanation in causal inference: Methods for mediation and interaction. New York, NY, US: Oxford University Press.

Schultz, P.W., Estrada, E., Schmitt, J., Sokoloski, R. \& Silva-Send, N. (2015). Using in-home displays to provide smart meter feedback about household electricity consumption: A randomized control trial comparing kilowatts, costs and social norms, Energy, 90, 351-358.

Wilhite, H. \& Ling, R. (1995). Measured energy savings from a more informative energy bills, Energy and Buildings, 22 $145-155$. 